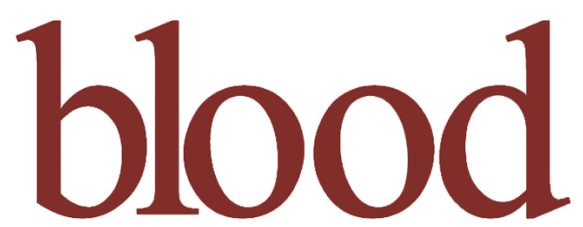

1985 65: 655-662

\title{
Effects of in vitro purging with 4-hydroperoxycyclophosphamide on the hematopoietic and microenvironmental elements of human bone marrow
}

S Siena, H Castro-Malaspina, SC Gulati, L Lu, MO Colvin, BD Clarkson, RJ O'Reilly and MA Moore

Information about reproducing this article in parts or in its entirety may be found online at:

http://bloodjournal.hematologylibrary.org/site/misc/rights.xhtml\#repub_requests

Information about ordering reprints may be found online at:

http://bloodjournal.hematologylibrary.org/site/misc/rights.xhtml\#reprints

Information about subscriptions and ASH membership may be found online at:

http://bloodjournal.hematologylibrary.org/site/subscriptions/index.xhtml

Blood (print ISSN 0006-4971, online ISSN 1528-0020), is published weekly by the American Society of Hematology, 2021 L St, NW, Suite 900, Washington DC 20036.

Copyright 2011 by The American Society of Hematology; all rights reserved.

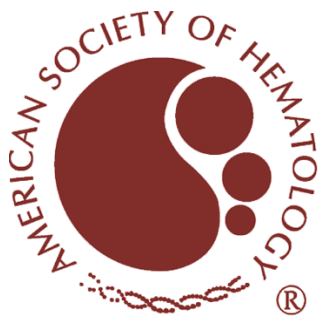




\title{
Effects of In Vitro Purging With 4-Hydroperoxycyclophosphamide on the Hematopoietic and Microenvironmental Elements of Human Bone Marrow
}

\author{
By Salvatore Siena, Hugo Castro-Malaspina, Subhash C. Gulati, Li Lu, Michael O. Colvin, Bayard D. Clarkson, \\ Richard J. O'Reilly, and Malcolm A.S. Moore
}

\begin{abstract}
We describe the effects of 4-hydroperoxycyclophosphamide (4-HC) on the hematopoietic and stromal elements of human bone marrow. Marrow cells were exposed to 4-HC and then assayed for mixed (CFU-Mix), erythroid (BFU-E), granulomonocytic (CFU-GM), and marrow fibroblast (CFUF) colony-forming cells and studied in the long-term marrow culture (LTMC) system. The inhibition of colony formation by 4-HC was dose and cell-concentration dependent. The cell most sensitive to 4-HC was CFU-Mix $\left(1 D_{50} 31\right.$ $\mu \mathrm{mol} / \mathrm{L})$ followed by BFU-E (ID $51 \mu \mathrm{mol} / \mathrm{L})$, CFU-GM (ID $89 \mu \mathrm{mol} / \mathrm{L})$, and CFU-F (ID $50235 \mu \mathrm{mol} / \mathrm{L})$. In LTMC, a dose-related inhibition of CFU-GM production was noted. Marrows treated with $300 \mu \mathrm{mol} / \mathrm{L}$ 4-HC were completely depleted of CFU-GM but were able to generate these progenitors in LTMC. Marrow stromal progenitors giving rise to stromal layers in LTMC, although less sensitive to 4-HC cytotoxicity, were damaged by 4-HC also in a doserelated manner. Marrows treated with 4-HC up to 300
\end{abstract}

\section{4} -HYDROPEROXYCYCLOPHOSPHAMIDE (4-HC) is a derivative of cyclophosphamide that exhibits in vitro chemical and biologic properties similar to those of microsomally activated cyclophosphamide. ${ }^{1.2}$ In 1980, Sharkis et $\mathrm{al}^{3}$ showed that 4-HC can selectively purge murine acute leukemia cells from marrow suspensions in a dose-related manner without affecting the viability and self-renewal capacity of the nonleukemic pluripotential hematopoietic stem cells (CFU-s). These studies provided the rationale for the application of 4-HC purged autologous bone marrow transplantation to the treatment of human leukemia and lymphoma. ${ }^{5}$ Thus autologous bone marrow harvested in remission, which has high risk of being contaminated with microscopically undetectable malignant cells, can be purged in vitro with 4-HC and then reinfused to reverse the lethal aplasia induced by preceding ablative chemoradiotherapy. ${ }^{4.5}$

The successful engraftment of transplanted bone marrow requires, besides intact primitive hematopoietic stem cells, a functional microenvironment or stroma in which hematopoietic stem cells can selfreplicate and differentiate. ${ }^{6.7}$ In humans, the marrow stromal cell (MSC) population comprises fibroblasts, endothelial cells, adipocytes, and macrophages..$^{8-10}$ Recent studies have shown that the stromal cells forming the in vitro microenvironment in human Dexter-type long-term marrow culture (LTMC) generated from marrow aspirates of allogeneic marrow transplant recipients are of donor origin and that the $\mu \mathrm{mol} / \mathrm{L}$, gave rise to stromal layers composed of fibroblasts, endothelial cells, adipocytes, and macrophages. Cocultivation experiments with freshly isolated autologous hematopoietic cells showed that stromal layers derived from 4-HC-treated marrows were capable of sustaining the long-term production of CFU-GM as well as controls. In conclusion: (1) Hematopoietic progenitors cells, CFU-Mix. BFU-E, and CFU-GM, are highly sensitive to 4-HC, whereas marrow stromal progenitor cells are relatively resistant. (2) Marrows treated with $300 \mu \mathrm{mol} / \mathrm{L}$ 4-HC that are depleted of CFU-Mix, BFU-E, and CFU-GM can generate CFU-GM in LTMC, suggesting that most primitive hematopoietic stem cells (not represented by CFU-Mix) are spared by 4-HC up to this dose. (3) Consequently, the above colony assays are not suitable tools for predicting pluripotent stem cell survival after 4-HC treatment in vitro. Q 1985 by Grune \& Stratton, Inc.

percentage of donor cells contributing to the culture stromal microenvironment progressively increases in marrow aspirates taken at greater times after transplantation." Although no evidence has been provided that the proliferation of donor MSCs in vivo is necessary to support grafted hematopoietic cells, it is conceivable that transplantation of MSCs constitutes a factor of critical functional significance. ${ }^{12}$

The studies presented here were aimed at evaluating the effects of 4-HC on the hematopoietic stem cells and stromal elements of human bone marrow. Evidence is presented demonstrating that multipotential (CFU-Mix) and erythroid (BFU-E) colony-forming cells are highly sensitive to the cytotoxic effect of 4-HC. In contrast, MSCs are relatively resistant and not functionally affected by the doses of $4-\mathrm{HC}$ currently used for purging autologous bone marrow.

From the Memorial Sloan-Kettering Cancer Center, Laboratories of Developmental Hematopoiesis, Hematopoietic Cell Kinetics. and Bone Marrow Transplantation Service. New York, and The Johns Hopkins Oncology Center, Baltimore.

Supported by grants No. ACS-CH-201 from the American Cancer Society: and CA-08748, CA-20194, CA-17353 from the National Cancer Institute; by the Gar Reichman Foundation; and by the Shenker Foundation for Cancer Research.

Submitted Dec 2, 1983; accepted Sept 17, 1984

Address reprint requests to Dr Hugo Castro-Malaspina, Bone Marrow Transplantation Service, Memorial Sloan-Kettering Cancer Center, 1275 York Ave, New York, NY 10021.

(c) 1985 by Grune \& Stratton. Inc.

$0006-4971 / 85 / 6503-0022 \$ 03.00 / 0$ 


\section{MATERIALS AND METHODS}

\section{Bone Marrow Cells}

Bone marrow cells were obtained by aspiration from the iliac crest of healthy volunteers who gave informed written consent. Preservation-free heparin was used as anti-coagulant (Weddel Pharmaceuticals Ltd, London). Buffy coats were collected after centrifugation of the aspirates at $200 \mathrm{~g}$ for ten minutes. Cells were washed and resuspended in alpha modification of Eagle's medium (Flow Laboratories, Hamden, Conn) supplemented with $10 \%$ fetal calf serum ([FCS] Sterile Systems, Logan, Utah).

\section{4-Hydroperoxycyclophosphamide and Incubation Procedure}

The 4-HC (mol wt 292) used in the present experiments was prepared by Dr Michael O. Colvin (from the Johns Hopkins Oncology Center, Baltimore). The synthesis and purification procedures have been described elsewhere.' The 4-HC powder was dissolved in calcium- and magnesium-free phosphate-buffered solution (PBS), then sterilized by filtration, and used within 30 minutes.

Marrow buffy coat cells at a final concentration of 10 or $20 \times 10^{6}$ cells per milliliter were incubated at $37^{\circ} \mathrm{C}$ for 30 minutes with 25 to $500 \mu \mathrm{mol} / \mathrm{L} 4-\mathrm{HC}$ and medium control. The cell suspensions were then washed at $10^{\circ} \mathrm{C}$ and assayed for colony-forming cells or inoculated for long-term culture according to the experimental design. The incubation procedure was similar to the one used for clinical trials of 4-HC-purged autologous marrow transplantation. Ten percent FCS was constantly included in all marrow suspensions. Viability was not significantly changed by the incubation procedure.

\section{Colony Assays}

Mixed and erythroid colony-forming cells. The assay for CFUMix was carried out according to the method of Fauser and Messner ${ }^{13}$ as described previously. ${ }^{14}$ Control and 4-HC-treated bone marrow cells were plated at $2 \times 10^{5}$ in $35-\mathrm{mm}$ tissue culture dishes (Lux Scientific Co, Newburg, Calif) containing a 1-mL mixture of Iscove's modified Dulbecco medium, $1 \%$ methyl-cellulose, $30 \%$ FCS, $5 \%$ medium conditioned by leukocytes in the presence of $1 \%$ phytohemagglutinin (HA-15, Wellcome Reagents Ltd, Wellcome Research Laboratories, Detroit) and $5 \times 10^{-5} \mathrm{~mol} / \mathrm{L} \mathrm{2-mercapto-}$ ethanol and 1 unit of a step III preparation of sheep plasma erythropoietin (Connaught Laboratories Ltd, Willowdale, Ontario, Canada). Dishes were incubated at $37^{\circ} \mathrm{C}$ in a humidified atmosphere flushed with $5 \% \mathrm{CO}_{2}$ in air. CFU-Mix were scored with an inverted microscope after 14 days of incubation and were identified further by plucking out colonies with a fine pipette and staining with benzidine and/or Wright-Giemsa stain. CFU-Mix usually contained erythroid, granulocyte, monocytic, and megakaryocytic cells. BFUE were scored from the same plates.

Granulocyte-macrophage colony-forming cells. Colony (more than 50 cells per aggregate) and cluster (three to 50 cells per aggregate) formation of control and 4-HC-treated bone marrow cells were stimulated by $10 \%$ exogenously supplied granulocytemacrophage colony-stimulatory factors present in medium conditioned by the human monocytic cell line GCT (GIBCO Laboratories, Grand Island, NY). Control and 4-HC-treated cells were plated at $2 \times 10^{5}$ in $1 \mathrm{~mL}$ of $0.3 \%$ agar culture medium (Difco Labs, Detroit) that included McCoy's 5A medium supplemented with essential and nonessential amino acids, glutamine, serine, asparagine, sodium pyruvate (GIBCO) as well as $10 \%$ heat-inactivated fetal bovine serum. Cultures were incubated at $37^{\circ} \mathrm{C}$ in a humidified atmosphere of $5 \% \mathrm{CO}_{2}$ in air and scored for colonies and clusters after seven days of incubation.

Fibroblast colony-forming cells. The general procedure has been described previously. ${ }^{15.16}$ Briefly, control and 4-HC-treated marrow cells resuspended in alpha-medium supplemented with $20 \%$ FCS, penicillin $(100 \mathrm{U} / \mathrm{mL})$, and streptomycin $(100 \mu \mathrm{g} / \mathrm{mL})$ were cultured in T-75 tissue culture flasks (Corning Glass Works, Corning, NY). Five $\times 10^{6}$ cells were incubated per flask; three flasks were used per point. The flasks were gassed with $5 \% \mathrm{CO}_{2}$ in air and incubated at $37^{\circ} \mathrm{C}$. The culture medium was totally renewed on day 4. After ten days of incubation, the cultures were stopped. For scoring fibroblast colonies, the flasks were stained with WrightGiemsa stain and examined with an inverted microscope at $25 x$. Fibroblastoid cell aggregates of more than 50 cells were scored as CFU-F. The fibroblastic nature of cells composing the colonies was demonstrated by immunofluorescence staining with antibodies against fibronectin and types I and III collagen as described previously. ${ }^{15.16}$

\section{Long-term Marrow Cultures}

LTMCs were established according to the method of Moore et al $^{17.18}$ as modified by Gartner and Kaplan. ${ }^{19}$ Twenty to forty $\times 10^{6}$ control and 100,300 , and $400 \mu \mathrm{mol} / \mathrm{L} 4-\mathrm{HC}$-treated marrow buffy coat cells in $10 \mathrm{~mL}$ of LTMC medium were inoculated into T-25 tissue culture flasks. The cultures were then gassed with $5 \% \mathrm{CO}_{2}$ in air and incubated at $33^{\circ} \mathrm{C}$. The LTMC medium consisted of McCoy's 5A medium supplemented with $1 \%$ minimal essential medium (MEM) sodium pyruvate solution, $0.8 \%$ MEM essential amino acids solution, $0.4 \% \mathrm{MEM}$ nonessential amino acids solution, $1 \%$ MEM vitamins solution, $1 \%$ penicillin-streptomycin solution, $1 \%$ glutamine-asparagine-serine solution, $12.5 \%$ horse serum, $12.5 \%$ FCS, and $10^{-6} \mathrm{~mol} / \mathrm{L}$ hydrocortisone sodium succinate. On day 3 of incubation, in order to eliminate the contaminating erythrocytes and mature myeloid cells, the nonadherent cells were gently aspirated out of the flasks and enriched for mononuclear cells by neutral density centrifugation in an isotonic sterile Percoll solution (1.074 $\mathrm{g} / \mathrm{mL}, 270$ mosm) (Pharmacia Fine Chemicals, Piscataway, NJ) as described previously. ${ }^{20}$ The resulting buoyant, mononuclear cellenriched fraction was collected, washed twice, resuspended in $5 \mathrm{~mL}$ of LTMC medium, and reinoculated into the original flasks containing the adherent stromal layers and fresh LTMC medium. The latter was added ( $5 \mathrm{~mL}$ per flask) soon after the nonadherent cells were aspirated out of the flasks. At weekly intervals, half the supernatant medium and suspension cells were removed and replaced with fresh LTMC medium. Cells in suspension were counted, checked for viability by trypan blue dye exclusion test, and assayed for CFUGM. Individual LTMCs were examined every seven days under a phase contrast inverted microscope, and the percentage of the flask surface covered by a stromal interlocking network was semiquantitatively assessed. Grades 1 through 4 corresponded to $25 \%$ to $100 \%$ of the base of each flask that was covered by a stromal network. At the time of stopping the culture (week 6 to 7), the CFU-GM content of the adherent layers derived from control and 4-HC-treated marrows was assessed using the following procedure. Individual flasks were gently washed twice to remove remaining nonadherent cells, and 2 $\mathrm{mL}$ of a $0.01 \%$ (wt/vol) $\mathrm{Ca}^{++}-\mathrm{Mg}^{++}$-free trypsin (GIBCO) solution was added to the flask and it was incubated at $4^{\circ} \mathrm{C}$ for 15 to 20 minutes. The cells that had been detached by the trypsin treatment (80\% to $90 \%$ of the adherent fraction) were aspirated out from the flask, diluted 1:1 with McCoy's medium containing 10\% FCS, counted, and assayed for CFU-GM as the nonadherent cell fraction. In independent experiments using fresh marrow buffy coat cells, this trypsin treatment inhibited the CFU-GM growth by less than $5 \%$.

To assess the capacity of the stromal layers established from 100 
$\mu \mathrm{mol} / \mathrm{L} 4-\mathrm{HC}$-treated marrows to sustain hematopoiesis in vitro, five-week-old primary LTMCs were totally depleted of all suspension cells, and a second inoculum of autologous bone marrow was added. This consisted of $20 \times 10^{6}$ light-density $(<1.074 \mathrm{~g} / \mathrm{mL})$ Percoll-separated nonadherent autologous marrow cells. Percollseparated cells were allowed to adhere to the bottom of T-75 tissue culture flasks at $37^{\circ} \mathrm{C}$ twice, for one hour each time. After adherence, the nonadherent light-density (NAL) autologous cells were extensively washed and added as dispersed single-cell suspension in fresh LTMC medium. The experimental groups included (a) NAL cells on stromal layers from 4-HC-treated marrow, (b) cell-free LTMC medium on stromal layers from 4-HC-treated marrow, (c) NAL cells in LTMC medium without any stromal layer, (d) NAL cells on control stromal layers, and (e) cell-free LTMC medium on control stromal layers. Cultures were demipopulated weekly and fed with the same amount of fresh LTMC medium. The total cell counts and CFU-GM numbers per flask were determined weekly.

\section{Immunocytochemical Analysis of the Adherent Layer of LTMCS}

The heterogeneity of the cells constituting the adherent layer of LTMCs established with 4-HC-treated marrow was assessed by immunofluorescence (IMF) methods using specific antibodies directed against components known to be associated with fibroblasts, endothelial cells, and macrophages as described previously. ${ }^{15.16 .21}$ These studies were performed in situ after the removal of the upper portion of culture flasks with a heated scalpel and double washing with PBS, pH 7.4.

Fibroblasts were identified by rabbit antibodies to type III collagen (kindly provided by $\operatorname{Dr} \mathrm{S}$. Gay from the University of Alabama) and human fibronectin (Bethesda Research Laboratories, Gaithersburg, Md). Endothelial cells were identified by rabbit antiserum to human factor VIII-related protein (CalbiochemBehring, San Diego). Macrophages were identified by mouse monoclonal antibodies to human monocytes (Bethesda Research Labs). Furthermore, the distribution of lipid-containing cells was studied using the oil red 0 staining for neutral fat as elsewhere described. ${ }^{22}$

\section{RESULTS}

Effect of 4-Hydroperoxycyclophosphamide on Multipotential, Erythroid, and Granulocyte-Macrophage Colony-Forming Cells

The percentage of recovery of CFU-Mix, BFU-E, and CFU-GM in comparison to that of CFU-F is depicted in Fig 1. Treatment of marrow buffy coat cells at $20 \times 10^{6}$ cells per milliliter with $100 \mu \mathrm{mol} / \mathrm{L}$ $4-\mathrm{HC}$ resulted in $100 \% \pm 0 \%, 97 \% \pm 1 \%, 71 \% \pm 6 \%$, and $17 \% \pm 7 \%$ inhibition of CFU-Mix, BFU-E, CFUGM, and CFU-F formation, respectively. Treatment with doses higher than those indicated in Fig 1, ie, 150,

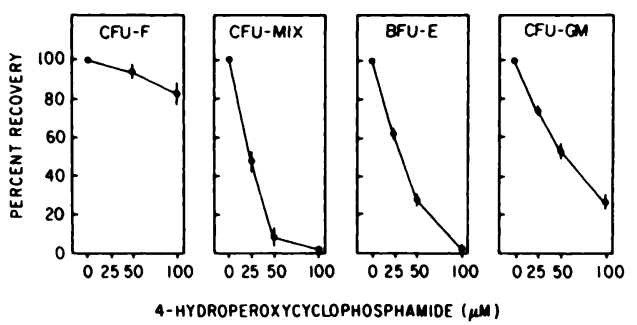

Fig 1. Comparison of the effect of 4-HC on human marrow stromal and hematopoietic progenitor cells. Marrow cells were incubated with 4-HC, washed, and then assayed for fibroblast (CFU-F), mixed (CFU-Mix), erythroid (BFU-E), and granulocytemacrophage (CFU-GM) colony-forming cells. Values shown are the mean \pm SEM from four (CFU-GM) and three (CFU-Mix, BFU-E) separate experiments and are expressed as percentage of control values. The control for CFU-Mix was $10.3 \pm 0.9$; BFU-E, $98 \pm 26$; CFU-GM, $79 \pm 23$; CFU-F, $91 \pm 11$. Note that CFU-F are relatively resistant to 4-HC as compared with CFU-Mix, BFU-E, and CFUGM.

200,300 , and $500 \mu \mathrm{mol} / \mathrm{L} 4-\mathrm{HC}$, resulted in $80 \% \pm$ $2 \%, 96 \% \pm 2 \%, 99.0 \% \pm 0.5 \%$, and $100 \% \pm 0 \%$ inhibition of CFU-GM growth. The ID $_{50}$ of CFU-Mix, BFU-E, and CFU-GM formation was 31,41 , and 89 $\mu \mathrm{mol} / \mathrm{L}$ 4-HC.

Treatment of marrow buffy coat cells at a lower cell concentration, ie, $10 \times 10^{6}$ per milliliter, with 50,100 , $150,200,300$, and $500 \mu \mathrm{mol} / \mathrm{L} 4-\mathrm{HC}$ resulted in $59 \% \pm 19 \%, 87 \% \pm 5 \%, 96 \% \pm 2 \%, 99.0 \% \pm 0.5 \%$, $100 \% \pm 0 \%$, and $100 \% \pm 0 \%$ inhibition of CFU-GM growth, respectively. The $\mathrm{ID}_{50}$ of CFU-GM formation was $22 \mu \mathrm{mol} / \mathrm{L} 4-\mathrm{HC}$.

When $25 \mu \mathrm{mol} / \mathrm{L} 4-\mathrm{HC}$-treated marrow cells were mixed at different ratios with autologous untreated marrow buffy coat cells and plated for CFU-GM, BFU-E, and CFU-Mix, the observed number of colonies closely corresponded to the expected values calculated on the basis of dilution in the cell mixtures (Table 1).

\section{Effect of 4-Hydroperoxycyclophosphamide on Marrow Fibroblast Colony-Forming Cells}

The percentage of recovery of CFU-F after incubation with 50 to $500 \mu \mathrm{mol} / \mathrm{L} 4-\mathrm{HC}$ is shown in Fig 2 . The pattern of recovery was clearly dose and cellconcentration dependent. The dose of 4-HC inhibiting $50 \%\left(I_{50}\right)$ of the growth of CFU-F was $235 \mu \mathrm{mol} / \mathrm{L}$

Table 1. Influence of Untreated Marrow Cells on CFU-GM. BFU-E, and CFU-Mix Growth From 4-HC-Treated Human Bone Marrow

\begin{tabular}{|c|c|c|c|c|c|c|c|c|c|}
\hline \multirow{2}{*}{$\begin{array}{l}\text { 4-HC-Treated-Untreated } \\
\text { Ratio of Cultured Cells }\end{array}$} & \multicolumn{3}{|c|}{ CFU-GM per $10^{5}$ Cells } & \multicolumn{3}{|c|}{ BFU-E per $2 \times 10^{5}$ Cells } & \multicolumn{3}{|c|}{ CFU-Mix per $5 \times 10^{5}$ Cells } \\
\hline & Observed & Expected & O/E & Observed & Expected & O/E & Observed & Expected & O/E \\
\hline $3: 0$ & 27.2 & - & - & 55 & - & - & 3.5 & - & - \\
\hline $2: 1$ & 39.9 & 41.5 & 0.96 & 60 & 58.2 & 1.03 & 4.0 & 5.0 & 0.80 \\
\hline $1: 1$ & 51.0 & 48.7 & 1.04 & 63 & 60.0 & 1.05 & 6.5 & 6.0 & 1.08 \\
\hline $1: 2$ & 53.7 & 55.8 & 0.96 & 66 & 61.6 & 1.07 & 6.1 & 6.7 & 0.91 \\
\hline $0: 3$ & 70.2 & - & - & 65 & - & - & 8.5 & - & - \\
\hline
\end{tabular}

O/E, observed-expected ratio. 


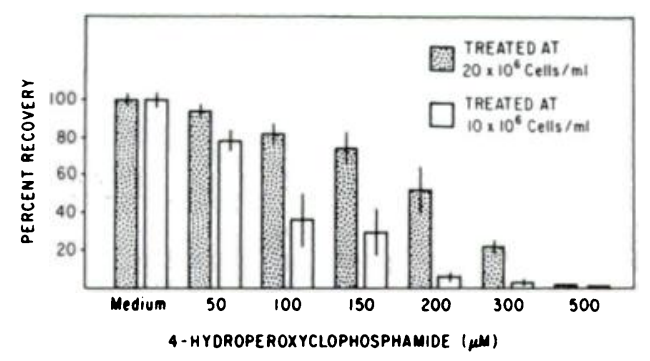

Fig 2. Effect of 4-HC on human marrow fibroblast colonyforming cells. Marrow cells were incubated with 4-HC, washed, and then assayed for CFU-F. Values shown are the mean \pm SEM from five separate experiments and are expressed as percentage of control values. The control CFU-F was $91 \pm 11$. Note that the toxic effect of 4-HC is dose and cell-concentration dependent.

when the cells were treated at a final concentration of $20 \times 10^{6}$ cells per milliliter. The ID $_{50}$ was $115 \mu \mathrm{mol} / \mathrm{L}$ when the incubation with $4-\mathrm{HC}$ was carried out at $10 \times 10^{6}$ cells per milliliter. Thus treatment at a higher cell concentration resulted in a lower cytotoxic effect of 4-HC on CFU-F.

\section{Establishment of LTMCs With \\ 4-Hydroperoxycyclophosphamide-Treated Bone Marrow}

Human bone marrows treated with 100 and 300 $\mu \mathrm{mol} / \mathrm{L} 4-\mathrm{HC}$ and then cultured in LTMC were ultimately capable of giving rise to an adherent stromal layer. In contrast, treatment of the same marrows with $400 \mu \mathrm{mol} / \mathrm{L} 4-\mathrm{HC}$ impaired their capacity to establish an LTMC. Figure 3 shows the stromal development in cultures of control and $100 \mu \mathrm{mol} / \mathrm{L}$ 4-HC-treated marrow as a percentage of the surface of the culture flask covered by the stromal network. At initial stages of culture, weeks 1 to 3 , the extent of the stromal layer derived from untreated marrow was more extensive. However, in the following weeks, when confluence was already reached in the untreated group, the 4-HC-treated stromal layers became progressively confluent and comparable to controls. Inoculation of a higher number of treated marrow cells

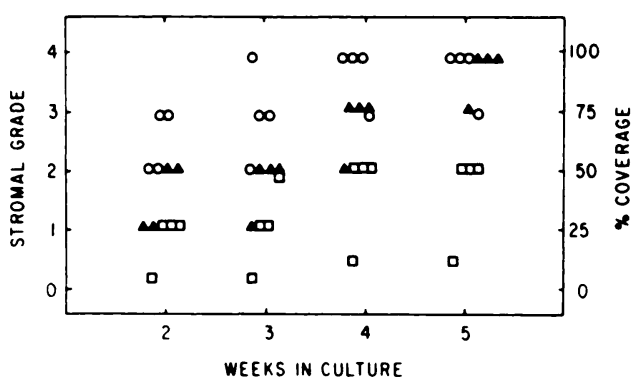

Fig 3. Stromal development in long-term cultures of 4-HCtreated human bone marrow. Marrow cells $\left(20 \times 10^{6}\right.$ per milliliter) were incubated with $100 \mu \mathrm{mol} / \mathrm{L}$ 4-HC, washed, and then inoculated for long-term culture. At weekly intervals, the stromal layer from experimental groups was graded by phase microscopy as described in Materials and Methods. Results are from four separate experiments, and each point represents the median score of triplicates. A heterogeneous stromal layer can be established after treatment with 4-HC, although a double number of 4-HC-treated cells is required to obtain a stromal layer similar to controls. $O$. Control: $20 \times 10^{6}$ cells/flask; $\square, 4-H C$ treated: $20 \times 10^{\circ}$ cells/ flask; $\triangle$, 4-HC treated: $40 \times 10^{6}$ cells/flask.

$\left(40 \times 10^{6}\right.$ per flask $)$ resulted in the formation of stromal layers equivalent in extent to those formed by $20 \times 10^{6}$ untreated marrow cells.

The analysis of the distribution and identify of the cells composing the stromal layer of five-week-old LTMCs established with $4-\mathrm{HC}$-treated marrows is shown in Table 2. In LTMCs derived from 100 and $300 \mu \mathrm{mol} / \mathrm{L} 4-\mathrm{HC}$-treated marrows, fibroblasts constituted the predominant ( $>75 \%)$ adherent cell population. Endothelial cells were found sparsely $(<10 \%)$ distributed within these stromal layers, except in one experiment among the $300 \mu \mathrm{mol} / \mathrm{L} 4-\mathrm{HC}$-treated group. Groups of lipid-containing cells were present in all cultures. Ten percent to $25 \%$ (three experiments) and $40 \%$ (one experiment) macrophages could be identified in the stromal layers derived from 100 $\mu \mathrm{mol} / \mathrm{L} 4-\mathrm{HC}$-treated marrows. Less than $10 \%$ (two experiments) and $10 \%$ to $25 \%$ (one experiment) macrophages were found in the stromal layers derived from $300 \mu \mathrm{mol} / \mathrm{L} 4-\mathrm{HC}$-treated marrows. In contrast, the in vitro stroma derived from $400 \mu \mathrm{mol} / \mathrm{L}$

Table 2. Extent and Composition of the Stromal Layers of Five-Week-Old Long-Term Cultures Derived From 4-HC-Treated Human Bone Marrow

\begin{tabular}{|c|c|c|c|c|c|c|c|c|c|c|c|c|c|c|c|}
\hline \multirow{2}{*}{$\begin{array}{c}\text { Experiment } \\
\text { No. }\end{array}$} & \multicolumn{5}{|c|}{$4-\mathrm{HC} 100 \mu \mathrm{mol} / \mathrm{L}$} & \multicolumn{5}{|c|}{$4-\mathrm{HC} 300 \mu \mathrm{mol} / \mathrm{L}$} & \multicolumn{5}{|c|}{$4-\mathrm{HC} 400 \mu \mathrm{mol} / \mathrm{L}$} \\
\hline & Curg & $F$ & EC & A & $M$ & Curg & $F$ & EC & A & $M$ & Curg & $F$ & EC & A & $M$ \\
\hline 1 & 100 & $+t+t$ & + & $+t$ & $+t$ & 75 & $+t+t$ & + & ++ & ++ & $<10$ & \pm & ND & - & - \\
\hline 2 & 100 & $+t+$ & + & ++ & $+t+$ & 75 & +++ & - & ++ & + & $<10$ & \pm & - & - & - \\
\hline 3 & 75 & $++t$ & + & $+t$ & $+t$ & 100 & $++t$ & + & ++ & + & $<10$ & - & ND & - & - \\
\hline 4 & 100 & $+t+t$ & + & ++ & $+t$ & & & & & & & & & & \\
\hline
\end{tabular}

A heterogeneous stromal layer derived from $20 \times 10^{6}$ untreated buffy-coat cells exhibits the following composition: fibroblasts, $3^{+}$to $4^{+}$; endothelial cells, \pm to $1^{+}$; adipocytes, $2^{+}$to $3^{+}$; macrophages $2^{+}$to $3^{+}$. All cultures were initiated with $40 \times 10^{6} 4-\mathrm{HC}-$ treated marrow buffy coat cells per flask.

Cvrg, percentage of coverage of culture flask surface; F, fibroblast; EC, endothelial cell; $A$, adipocyte; M, macrophage; ND, not determined; - O\%; ,$+<10 \% ;++, 10 \%$ to $25 \% ;+++.26 \%$ to $75 \% ;+++,>75 \%$. 
4-HC-treated marrows consisted only of a few scattered spots of fibroblasts (Table 2).

To assess the functional capacity of stromal layers established from 4-HC-treated marrow to sustain hematopoiesis in vitro, primary LTMCs were totally depleted of all suspension cells after five weeks, when the total CFU-GM produced per culture was reduced to $45 \pm 21$. Five groups of cultures were then initiated using a second addition of autologous NAL marrow cells (see Materials and Methods). As shown in Fig 4, no impairment in the production of CFU-GM was seen in the group involving the coculture of NAL cells with stromal layers from 4-HC-treated marrow as compared with stromal layers derived from untreated marrow. In flasks inoculated with NAL cells without any stromal support, the production of CFU-GM was remarkably lower and of short duration (Fig 4). In no instance were CFU-GM found in the nonadherent fraction of the flasks depopulated of all buoyant cells and not reinoculated with fresh NAL cells (not shown in Fig 4). This finding ruled out the possibility that control number of CFU-GM were released from the adherent layers derived from 4-HC-treated marrow.

The numbers of total CFU-GM and nonadherent cells in primary long-term cultures derived from control and 4-HC-treated marrows are summarized in Table 3. In comparison to control cultures, in the first two weeks the decline of the total nonadherent cell number was slower in the 100 and $300 \mu \mathrm{mol} / \mathrm{L}$ 4-HC-treated groups. Despite weekly demipopulation of the cultures, continuous production of CFU-GM could be detected in the nonadherent fraction of the $100 \mu \mathrm{mol} / \mathrm{L} 4-\mathrm{HC}$-treated group for five weeks. In the $300 \mu \mathrm{mol} / \mathrm{L} 4-\mathrm{HC}$-treated group, although the primary inoculum was virtually depleted of all CFU-GM $(0.16 \pm 0.20$ per culture $)$, a modest generation of these committed stem cells was found on week 1 and week 2 of culture. Treatment with $400 \mu \mathrm{mol} / \mathrm{L} 4-\mathrm{HC}$ abolished CFU-GM growth in LTMCs. On weeks 6 to 7 of culture, CFU-GM were occasionally found in the

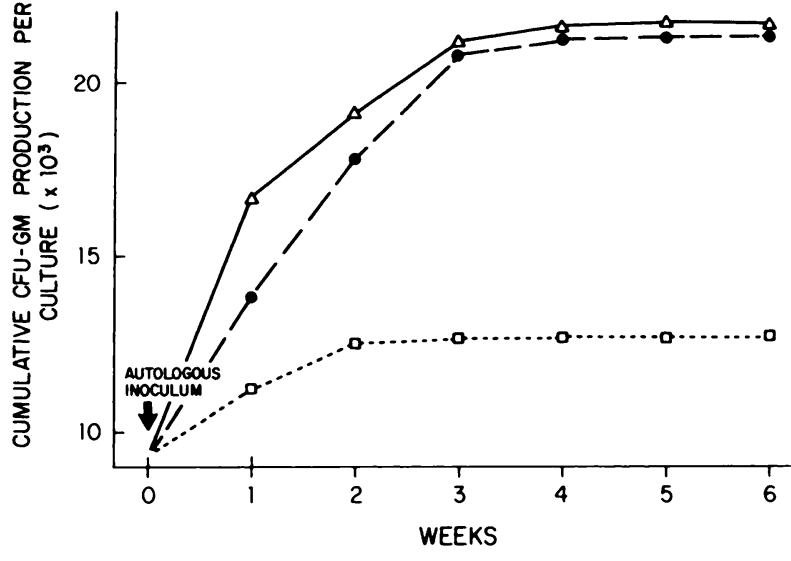

Fig 4. Sustained production of granulocyte-macrophage colony-forming cells on heterogeneous stromal layers derived from 4-HC-treated marrow. After depopulation of all suspension cells, $20 \times 10^{6}$ autologous NAL marrow cells were added to fiveweek-old stromal layers of long-term cultures initiated with $40 \times$ $10^{6}$ 4-HC-treated cells per flask. Cultures were demipopulated weekly, and the total cell counts and CFU-GM numbers per flask were determined. Each datum point represents the cumulative number of mean CFU-GM recovered from the cultures (two to three culture flasks per group). No correction was made for the depopulations owing to the weekly replacement of half the LTMC medium volume. In this representative experiment, the NAL cell inoculum containing $9.3 \times 10^{3} \mathrm{CFU}-\mathrm{GM}$ was added to 4-HCpretreated stromal layers $(0)$, non-pretreated stromal layers $(\Delta)$. and controls with no stromal layers ( $\square$ ). Heterogeneous stromal layers derived from 4-HC-treated marrow could sustain the longterm production of CFU-GM in a manner similar to controls. No CFU-GM growth was observed in additional controls with no added cells: layers from 4-HC-treated marrow and layers from non-pretreated marrow (data not shown in this figure).

adherent fraction of control LTMC, whereas in no instance could CFU-GM be detected in the LTMC derived from 4-HC-treated marrows.

\section{DISCUSSION}

Data presented in this paper show that the 4-HC doses currently used for marrow purging in autologous transplantation, although depleting the graft of hematopoietic progenitors, including the putative pluripo-

Table 3. Primary Long-term Cultures Derived From Control and 4-HC-Treated Human Bone Marrow

\begin{tabular}{|c|c|c|c|c|c|c|c|c|}
\hline \multirow[b]{3}{*}{ Week } & \multicolumn{4}{|c|}{ Total Nonadherent Cells per Culture $\left(\times 10^{5}\right)$} & \multicolumn{4}{|c|}{ Total CFU-GM per Culture } \\
\hline & \multirow{2}{*}{$\begin{array}{l}\text { Medium } \\
\text { Controlt }\end{array}$} & \multicolumn{3}{|c|}{ 4-HC $(\mu \mathrm{mol} / \mathrm{L}) \ddagger$} & \multirow{2}{*}{$\begin{array}{l}\text { Medium } \\
\text { Controlt }\end{array}$} & \multicolumn{3}{|c|}{ 4- $\mathrm{HC}(\mu \mathrm{mol} / \mathrm{L}) \ddagger$} \\
\hline & & 100 & 300 & 400 & & 100 & 300 & 400 \\
\hline 1 & $91 \pm 29$ & $76 \pm 19(41)$ & $25 \pm 20(14)$ & $17 \pm 10$ & $4,133 \pm 275$ & $1,312 \pm 387(16)$ & $13 \pm 7(<1)$ & 0 \\
\hline 2 & $34 \pm 11$ & $36 \pm 23(52)$ & $21 \pm 13(31)$ & $1.3 \pm 1.0$ & $1,828 \pm 321$ & $364 \pm 98(10)$ & $1.1 \pm 0.5(<1)$ & 0 \\
\hline 3 & $10 \pm 7$ & $6.6 \pm 1.5(33)$ & $1.5 \pm 1.0(7)$ & $0.3 \pm 0.1$ & $370 \pm 21$ & $116 \pm 36(16)$ & 0 & 0 \\
\hline 4 & $6 \pm 1$ & $3.6 \pm 3.0(30)$ & $0.8 \pm 0.5(7)$ & $0.3 \pm 0.1$ & $159 \pm 87$ & $38.3 \pm 19.0(12)$ & 0 & 0 \\
\hline 5 & $2 \pm 1$ & $0.6 \pm 0.5(15)$ & 0 & 0 & $45 \pm 21$ & $3.3 \pm 3.0(4)$ & ND & ND \\
\hline 6 & $0.6 \pm 0.5$ & 0 & 0 & 0 & $3.3 \pm 3.0$ & 0 & ND & ND \\
\hline
\end{tabular}

Mean \pm SEM of four $(100 \mu \mathrm{mol} / \mathrm{L} 4-\mathrm{HC})$ and three $\left(300\right.$ and $400 \mu \mathrm{mol} / \mathrm{L} \mathrm{4-HC)} \mathrm{separate} \mathrm{experiments.} \mathrm{All} \mathrm{cultures} \mathrm{were} \mathrm{incubated} \mathrm{at} 33{ }^{\circ} \mathrm{C}$ and subjected to removal of half the growth medium and nonadherent cells at weekly intervals. $\dagger$, primary inoculum $20 \times 10^{6} /$ per flask containing $9,164 \pm$

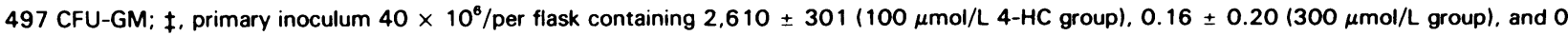
(400 $\mu \mathrm{mol} / \mathrm{L}$ group) CFU-GM; ( ), percentage of control cultures corrected for the number of initial inoculum; ND, not determined. 
tent stem cells or CFU-Mix, do not significantly affect the number and function of MSC. The dose of 4-HC used in clinical marrow purging is limited by its toxicity on hematopoietic stem cells. This has been estimated indirectly by assaying the frequency of CFU-GM in the harvested marrows before and after 4-HC treatment. ${ }^{23}$ Interestingly, clinical transplantation data have shown that despite CFU-GM depletion, 4-HC-purged autologous grafts retain their capacity to reconstitute the hematopoietic system of transplant patients pretreated with myeloablative chemoradiotherapy. ${ }^{4.5}$ This lack of correlation between in vitro CFU-GM recovery and in vivo marrow-repopulating ability suggests that (1) the measured CFU-GM does not reflect the survival of primitive pluripotential stem cells, or (2) the treatment with 4-HC causes the loss of an accessory cell(s) necessary for the in vitro but not for the in vivo growth of hematopoietic stem cells. To address the first possibility, we studied the 4-HC sensitivity of CFU-Mix, a progenitor cell with selfrenewal characteristics ${ }^{24-26}$ that has been considered the putative primitive stem cell. Our results demonstrate that CFU-Mix and BFU-E are even more 4-HC-sensitive than is CFU-GM. The possibility that 4-HC is toxic to an accessory cell(s) necessary for the in vitro growth of hematopoietic stem cells was ruled out by the results of mixing experiments (4-HCtreated + untreated marrow cells at various ratios). Therefore, the CFU-Mix assay also appears to be an unsuitable tool for predicting the engraftment capability of 4-HC-purged grafts. Moreover, the fact that 100 and $300 \mu \mathrm{mol} / \mathrm{L} 4-\mathrm{HC}$-treated bone marrow (ie, depleted of CFU-Mix) can reinstitute full hematopoietic function in supralethally irradiated patients ${ }^{4.5}$ indicates that CFU-Mix does not represent the stem cell responsible for hematopoietic reconstitution of the transplanted host and suggests that there are early pluripotent stem cells that are significantly less affected by $4-\mathrm{HC}$.

In an attempt to shed further light on the sensitivity of early hematopoietic stem cells, we measured the production of CFU-GM in primary LTMCs derived from control and 4-HC-treated marrow. Despite weekly demipopulation of the cultures, CFU-GM could be detected in the nonadherent fraction up to week 5 (100 $\mu \mathrm{mol} / \mathrm{L} 4-\mathrm{HC}$-treated group) and week 2 (300 $\mu \mathrm{mol} / \mathrm{L} \mathrm{4-HC-treated} \mathrm{group)} \mathrm{of} \mathrm{culture.} \mathrm{In} \mathrm{the}$ latter group, a low number of CFU-GM was generated despite almost complete CFU-GM depletion in the initial inoculum. In contrast, $400 \mu \mathrm{mol} / \mathrm{L} 4-\mathrm{HC}-$ treated marrows failed in all instances to generate any CFU-GM. These data suggest that the primitive pluripotent stem cells are affected by $4-\mathrm{HC}$ also in a dose-related manner but to a lesser degree than the more differentiated hematopoietic stem cells, since their capacity to proliferate and differentiate into CFU-GM is spared by treatment with 4-HC up to 300 $\mu \mathrm{mol} / \mathrm{L}$. Two lines of evidence support this notion. First, previous studies by our group have shown that the probable human pluripotent stem cells that are detected in LTMC are Ia-antigen-negative, ${ }^{18}$ whereas human CFU-Mix are Ia-antigen-positive. ${ }^{14}$ This difference suggests that the two assays detect distinct cells within a hierarchy of stem cell differentiation, proliferation, and self-renewal capacity. Second, Botnick et $\mathrm{al}^{27}$ in mice and Smith et $\mathrm{al}^{28}$ in humans have shown that very-high-dose cyclophosphamide administration in vivo results in rapid depletion of committed hematopoietic stem cells and pancytopenia, which is followed by prompt hematologic recovery. These findings imply that cyclophosphamide or derivatives are more sparing of the most primitive hematopoietic stem cells.

Assessment of the effects of $4-\mathrm{HC}$ on the MSC compartment by the LTMC system and the CFU-F assay showed that human MSCs are quantitatively but not functionally affected by the in vitro procedures for marrow purging with 4-HC. The unique adherent stromal layer found in the LTMC system is deemed necessary for continuing in vitro hematopoiesis and is the closest laboratory equivalent to its in vivo counterpart. In that marrow fibroblasts constitute the predominant cell population of MSCs and appear to play a significant role in regulation and differentiation of hematopoietic stem cells, ${ }^{29-33}$ we used the CFU-F assay to quantitate the changes occurring on marrow fibroblast progenitors after treatment with 4-HC. In contrast to hematopoietic progenitors, MSCs are relatively resistant to the in vitro action of 4-HC. In fact, much higher 4-HC doses (CFU-F ID ID $_{50} 235 \mu \mathrm{mol} / \mathrm{L}$ 4-HC $v$ CFU-Mix ID I $_{50} 31 \mu \mathrm{mol} / \mathrm{L} \mathrm{4-HC)}$ are required to abolish the formation of colonies by CFU-F as well as the capacity of 4-HC-treated marrow suspensions to give rise to functional and heterogeneous stromal layers in LTMC. Furthermore, because the 4-HC cytotoxicity was dose dependent on CFU-F as well as on the stromal progenitors giving rise to LTMC adherent layers, it is possible that the CFU-F assay might reflect, as well as the frequency of fibroblasts, the frequency of the other components of the marrow stromal population in the bone marrow graft. In addition to measuring the direct toxic effect of 4-HC on MSCs, we tested the functional capacity of stromal layers derived from 4-HC-treated marrows by assessing their capacity to support long-term hematopoiesis. Such stromal layers did indeed support the long-term production of CFU-GM in a manner similar to controls, indicating that $4-\mathrm{HC}$ treatment spares enough 
MSCs to be capable of giving rise to heterogeneous stromal layers having a normal hematopoietic functional activity. Hilton has recently suggested, on the basis of studies done on human and rodent leukemia cell lines, that the intracellular aldehyde dehydrogenase (AHD) activity is directly correlated with cyclophosphamide resistance. ${ }^{34.35}$ Whether human MSCs and pluripotent hematopoietic stem cells possess high AHD activity responsible for their 4-HC resistance remains to be established.

Presinus_studies nn murine proprimenta models number of patients with small-cell lung carcinoma ${ }^{28}$ and aplastic anemia have shown recovery of autologous bone marrow function after cyclophosphamide in maximally tolerated doses (ie, higher doses cause fatal cardiac necrosis). ${ }^{40-43}$ Our data, in accordance with these in vivo observations, indicate that doses of 4-HC currently used in vitro for autologous human marrow transplantation have a minor quantitative toxic effect on MSCs with no significant functional damage.

The data presented in this paper and the observation tbathematnanietic resenstitutinn arsurs a fter the infl"- 
20. Pelus LM, Saletan S, Silver RT, Moore MAS: Expression of Ia-antigens on normal chronic myeloid leukemic human granulocyte-macrophage colony forming cells (CFU-GM) is associated with the regulation of cell proliferation by prostaglandin E. Blood 59:284, 1982

21. Castro-Malaspina H, Saletan S, Gay RE, Oettgen B, Gay S, Moore MAS: Immunocytochemical identification of cells comprising the adherent layer of long-term human bone marrow cultures. Blood 58:107a, 1981 (abstr)

22. Lillie RD, Ashburn LL: Supersaturated solutions of fat stains in dilute isopropanol for demonstration of acute fatty degeneration not shown by Herxeheimer's technique. Arch Pathol 36:432, 1943

23. Korbling M, Hess AD, Tutscka PJ, Kaizer H, Colvin MO, Santos GW: 4-Hydroperoxycyclophosphamide: A model for eliminating residual human tumor cells and $\mathrm{T}$-lymphocytes from the bone marrow graft. Br J Haematol 52:89, 1982

24. Messner HA, Fauser AA: Culture studies of pluripotential hemopoietic progenitors. Blut 41:327, 1980

25. Ash RC. Detrick RA, Zanjani ED: Studies of human pluripotential hemopoietic stem cells (CFU-GEMM) in vitro. Blood $58: 309,1981$

26. Humphries RK, Eaves AC, Eaves CJ: Self-renewal of hemopoietic stem cells during mixed colony formation in vitro. Proc Natl Acad Sci USA 78:3629, 1981

27. Botnick LE, Hannon EC, Vigneulle R, Hellman S: Differential effect of cytotoxic agents on hematopoietic progenitors. Cancer Res 41:2338, 1981

28. Smith IE, Evans BD, Harland SJ: High-dose cyclophosphamide $\left(7 \mathrm{~g} / \mathrm{m}^{2}\right)$ with or without autologous bone marrow rescue after conventional chemotherapy in the treatment of patients with small cell lung cancer. Cancer Treat Rev Suppl A 10:79, 1983

29. Friedenstein AJ, Chailakhyan RK, Latsinik NV, Panasyuk AK, Keiliss-Borok IV: Stromal cells responsible for transferring the microenvironment of the hemopoietic tissues. Transplantation 17:331, 1974

30. Kaneko S, Motomura S, Ibayashi H: Differentiation of human bone marrow-derived fibroblastoid colony forming cells (CFU-F) and their roles in hemopoiesis in vitro. $\mathrm{Br} \mathrm{J}$ Haematol $51: 217,1982$

31. Blackburn MJ, Goldman JM: Increased haematopoietic cell survival in vitro induced by a human marrow fibroblast factor. $\mathrm{Br} \mathrm{J}$ Haematol 48:117, 1981
32. Blackburn MJ, Goldman JM: Increased survival of haematopoietic progenitor cells in vitro induced by human marrow stromal cells, in Baum SJ, Ledney GD, Khan A (eds): Experimental Hematology Today. Basel, Kargerm, 1981, p 77

33. Gordon MY, Kearney L, Hibbin JA: Effects of human marrow stromal cells on proliferation by human granulocytic (GMCFC), erythroid (BFU-E) and mixed (Mix-CFC) colony forming cells. Br J Haematol 53:317, 1983

34. Hilton J, Cohen D: Role of aldehyde dehydrogenase in the response to L1210 cells to cyclophosphamide. Proc Am Assoc Cancer Res 23:169, 1983 (abstr)

35. Hilton J, Colvin M: The role of aldehyde dehydrogenase activity in cyclophosphamide sensitivity of hematopoietic and leukemic cell populations. Proc Am Assoc Cancer Res 25:339, 1984 (abstr)

36. Fried W, Husseini S, Gregory S, Knospe WH, Trobaugh FE: Effect of cyclophosphamide on the hematopoietic microenvironmental factors which influence hematopoietic stem cell proliferation. Cell Tissue Kinet 6:155, 1973

37. Fried W, Kedo A, Barone J: Effects of cyclophosphamide and of busulphan on spleen colony-forming units and on hematopoietic stroma. Cancer Res 37:1205, 1977

38. Fried W, Barone J: Residual marrow damage following therapy with cyclophosphamide. Exp Hematol 8:610, 1980

39. Wathen LM, Knapp SA, De Gowin RL: Suppression of marrow stromal cells and microenvironmental damage following sequential radiation and cyclophosphamide. Int J Radiat Biol 7:935, 1981

40. Baran DT, Griner PF, Klemperer MR: Recovery from aplastic anemia after treatment with cyclophosphamide. N Engl J Med 295:1522, 1976

41. Territo MC for the UCLA Bone Marrow Transplantation Team: Autologous bone marrow repopulation following high dose cyclophosphamide and allogeneic marrow transplantation in aplastic anemia. Br J Haematol 36:305, 1977

42. Sensebrenner LL, Steele AA, Santos GW: Recovery of hematologic competence without engraftment following attempted bone marrow transplantation in aplastic anemia. Exp Hematol 5:51, 1977

43. Gmur J, von Felten A, Rhyner K, Frick PG: Autologous hematologic recovery from aplastic anemia following high dose cyclophosphamide and HLA-matched allogeneic bone marrow transplantation. Acta Haematol (Basel) 62:20, 1979 